\title{
User Behavior of Mobile Enterprise Applications
}

\author{
Sangmin Lee L $^{\text {* }}$ \\ ${ }^{1}$ School of Business Administration, Soongsil University \\ Seoul 06978, South-Korea \\ [e-mail: sangmin_lee@ssu.ac.kr] \\ *Corresponding author: Sangmin Lee
}

Received May 8, 2016; revised July 4, 2016; accepted August 15, 2016;

published August 31, 2016

\begin{abstract}
Organizations have been implementing mobile applications that actually connect to their backend enterprise applications (e.g. ERP, SCM, etc.) in order to increase the enterprise mobility. However, most of the organizations are still struggling to fully satisfy their mobile application users with the enterprise mobility. Even though it has been regarded as the right direction that the traditional enterprise system should move on, the studies on the success model for mobile enterprise applications in user's acceptance perspective can hardly be found. Thus, this study focused not only to redefine the success of the mobile enterprise application in user's acceptance persepective, but also to find the impacts of the factors on user's usage behavior of the mobile enterprise applications. In order to achieve this, we adopted the Technology Acceptance Model 2 (TAM2) as a model to figure out the user's behavior on mobile applications. Among various mobile enterprise applications, this study chose mobile ERP since it is the most representing enterprise applications that many organizations have implemented in their backend. This study found that not all the constructs defined by Davis in TAM2 have a significant influence on user's behavior of the mobile-ERP applications. However, it is also found that most social influence processes of TAM2 influence user's perception of the degree of interaction by mobile-ERP applications.
\end{abstract}

Keywords: ICONI 2015, Mobile Enterprise Applications, M-ERP, User Acceptance Model, User Behavior, TAM2

A preliminary version of this paper was presented at ICONI 2015, and was selected as an outstanding paper. 


\section{Introduction}

The traditional enterprise system has been shifting in response to the drastic increase of mobile device usage in the enterprise. To increase the enterprise mobility, organizations have been implementing mobile applications that actually connect to their backend enterprise applications. These enterprise application includes the systems for Enterprise Resource Planning (ERP), Supply Chain Mangement (SCM), etc. However, most of the organizations are still in the early stage in terms of the enterprise mobility [1]. Even though it has been regarded as a right direction to move forward for the traditional enterprise system, the studies on the critical success factors (CSFs) or success model for mobile enterprise applications can be hardly found. For example, the clear definition of successful implementation of mobile enterprise resource planning apps (M-ERP) does not exist, and sometimes controversial. Considering M-ERP application implementation, as an IT project, project managers or M-ERP consultants may define the success in terms of completing the project on time and within budget [2]. The reason for this is that most ERP implementations are late or over budget [3]. In addition, 66 percent of ERP users from 192 U.S. companies had failed to realize more than half of its original expected benefits from their projects [4]. However, the on-time and within-budget implementation does not guarantee the success of mobile enterprise application development in terms of the user's satisfaction. Moreover, few studies have tried to investigate the successful implementation of the mobile enterprise application system from user's acceptance perspective.

The most significant characteristics of mobile applications and its related technologies are 'anytime' and 'anywhere'. According to a new forecast from International Data Corporation (IDC), the U.S. mobile worker population will grow at a steady rate over the next five years, increasing from 96.2 million in 2015 to 105.4 million mobile workers in 2020. By the end of the forecast period, IDC expects mobile workers will account for nearly three quarters (72.3\%) of the total U.S. workforce [5]. Along with competitive pressure in mobile technologies, it is one of the driving forces behind the rapid growth of mobile solutions in the field of business-to-business (B2B), employee-to-business (E2B), and business-to-employee (B2E) [6]. Mobile access to back-end enterprise systems could considerably lower operational costs while it increases flexibility and shorten response times. Eric Kimberling, managing partner at Panorama Consulting Solutions, said mobility continues to be a big trend. Executives and employees want real-time access to information, regardless of where they are. "Gone are the days of accessing ERP system from a single computer - now employees use phones and tablets just as much - if not more - than they do a computer or laptop" said Kimberling. Kimberling continued to state that vendors finally began to provide compelling and secure ways for employees to accomplish mobile solutions [7]. Leveraging mobile technology is suggested by increased mobility of users in order to improve prompt transaction and data collection for decision making that supports ERP systems [6].

Therefore, the purpose of this study is i) to redefine mobile enterprise application success in terms of the factors on user's accepatance, ii) to find the impacts of the factors on user's usage behavior of the applications. In order to achieve these objectives, this study adopted Technology Acceptance Model 2 (TAM2) into a research model to find how users come to accept and use a technology. The TAM2 suggests that when users are presented with a new technology, a number of factors that influence their decision about how and when they will use it, particularly Perceived Usefulness (PU) and Perceived Ease-of-Use (PEOU) [8]. Thus, this study focused on investigating user's intentions to use M-ERP application and their usage 
behavior based on mainly TAM2 model. In addition, we adopt one more factor that is critical for mobile app development environment based on the opinions from industry experts. The research results are expected to serve as a reference for those planning to start their business on M-ERP application.

\section{Related Work}

Previous studies related with to research backgrounds and variables are investigated in this section. In the early days of the smartphone revolution, employees used smartphones to stay connected to work email, and handle some other basic tasks. However, a more robust appications have been emerging in these days that opens up new possibilities for a mobile workforce. For M-ERP application users in an organization, especially salesforces, the usage of M-ERP application is critical. Salesforces can access their ERP systems from their smartphones, getting all the information they need without visiting their offices. In addition, service engineers can access product information and maintenance records anytime regardless of where they are [9]. Thus, it is obvious that M-ERP application cannot exist as a stand-alone. It is hardly implementable without having traditional ERP system in back-end. Therefore, it is worth to understand how the traditional ERP system has been evolved.

\subsection{Traditional ERP System}

Enterprise Resource Planning (ERP) tends to be a widely misunderstood concept. Koch wrote, “Forget about planning - it doesn't do much of that - and forget about resource, a throwaway term. But remember the enterprise part". He went on to state that the objective of ERP systems is to, "integrate all departments and functions across a company onto a single computer system that can serve all those different departments' particular needs” [10]. The implication is that the successful ERP system implementation will bring on higher levels of productivity, innovation, and profitability [11]. Thus, over the last decade, ERP has been implemented in lots of organizations worldwide [12], and companies have spent billions of dollars and huge amount of time implementing ERP systems [13]. A recent research finds that the total ERP market is expected to reach $\$ 41.69$ billion by 2020 [14].

However, the adoption of ERP systems has been slow in some industries and companies have reported unpleasant experiences with efforts to implement successful ERP systems in spite of its promised benefits. The costs and complexity in implementation are critical issues. ERP system implementation generally costs ranging from half a million to $\$ 300$ million, with an average cost of $\$ 15$ million [15]. Another problematic issue that has arisen for some companies concerns the changes in organizational culture that tend to accompany the implementation of ERP systems [16]. As a matter of fact, an ERP project not only tend to become complex to implement but also involves a broad range of organizational transformation process during the entire implementation process [17]. Another typical losses of the organizations are the loss of productivity emanating from operational inefficiencies and individual conflicts within the organizations [18]. To enhance the probability of ERP implementation success, organizations require relevant and accurate information related to best practices in ERP implementation [19]. Of equal importance to organizations is relevant and accurate information concerning what does not work well or at all in ERP implementation programs [20]. Such information, however, is not always easily located.

There are several models that advocates to enhance the probability of success in ERP implementation. However, various research designs were applied for those models. Hsiao, 
Yang, Lin, and Lee applied Six Sigma approaches to identify the key failure factors that are associated with the implementation of ERP systems [21]. The model provides important and useful information. It is incomplete, however, as best practices are not identified directly. Gefen and Ragowsky developed that focuses exclusively on manufacturing firms [22]. The model does, however, provide flexibility in relation to company size. The model, however, does not address failure factors, nor does it provide insights for other industries. The model developed by Zwikael and Globerson was oriented diametrically from the model developed by Hsiao, Yang, Lin, and Lee (2007) with respect to success factors and failure factors [23]. It focused extensively on success factors without providing sufficient emphasis on causes of failure in the implementation of ERP systems. Chung (2007) developed a model which defines the factors that enhanced the probability of ERP implementation success for an organization [24]. The strength of this model is that the essential research focused on success/failure factors related to the implementation of ERP systems. However, the Chung model focused the successful ERP implementation specifically on engineering and construction companies. Important work has been performed and is reported in the literature in relation to model development for the enhancement of success by organizations in the implementation of ERP systems. Unfortunately, none of the models appears to be universally applicable to a wide spectrum of organizations. Thus, organizations continue to confront a dilemma when considering the implementation of ERP systems. There is the risk on one side that stems from not implementing an ERP system. This risk is associated with a failure to act, and such failure could place an organization at a competitive disadvantage.

There also is a counter risk for organizations that move forward on an ERP implementation program that ends in failure or ineffectiveness. As opposed to placing the organization at a competitive disadvantage, the manifestation of the risks associated with an ineffective ERP implementation is direct out-of-pocket costs. Most organizations, thus, are still in need of a relevant and a reliable model to enhance the probability of success in an ERP implementation program. Definitely, successful ERP system implementation guarantees significant benefits for companies. In order to increase the probability of successful ERP system implementation, organizations should obtain the accurate data from the experience of what worked well when implementing the ERP project [25]. There have been many studies that focuses on the successful ERP implementation associated with identifying critical success factors.

\subsection{Mobile ERP System}

Handheld devices came into use as stand alone unites during the late 1990’s. Currently, due to the rapid adoption of mobile devices into the workplace, the ERP vendors have realized that they are unable to keep up with the needs of the growing mobile workforce with their existing functionality. As a result, the vendors have to build the new mobile applications by creating hybrid ERP systems - a combination of cloud services and mobile applications. While this brings mobile functionality to a wider market, it results in features being released as part of the regular vendor software lifecycle, forcing major upgrades just to implement mobile access. By using independent support to free up significant operating budget, organizations are using the savings to more quickly add mobile functionality from third-party mobility vendors, while extending the life of their ERP systems for 10 - 15 years [26].

The visibility across end to end business processes of accurate, timely, relevant, sufficient and cost effective data is also critical requirement for successful business integration [6]. Another key for the successful ERP implementation is integration of internal processes. The integration has to include basic information systems that connects the functionality of front office and that of the back office. The use of ERP systems in mobile devices with wireless 
technology is quite similar with those for supply chain management. Clemens et al. stated that the main differences between ERP and SCM are the broader scope of the data along with a broader range of ERP processes. Moreover, depending on the location of critical data such as human resources and financial data, more controls on both the server and client sides of the mobile applications are required in order to enhance the organization's security [6].

Enterprise mobility is defined as set of people, processes and technology that focused on managing mobile devices, mobile services, and wireless networks [27]. It becomes important discipline within the organization as more workers use smartphone and tablet devices in the workplace. It is obvious that the new mobile devices need an access to business information in ERP systems. It is an organization's responsibility to build a solid mobility platform by determining the best enterprise strategy for integrating mobile devices with business processes. Mobility extends Mobile ERP devices are becoming an important extension to ERP. The most benefit of mobility devices is extending the accessibility of ERP systems to employees, partners and even customers when and where they need it. The combination of mobile devices and ERP business systems empowers workers and makes it possible for them to engage more fully with their peers and customers [28].

\subsection{Technology Acceptance Model (TAM)}

Introduced by Davis in 1989, the Technology Acceptance Model (TAM) explains the various factors of computer use acceptance as they are related to specific user behavior. The goal of TAM is "to provide an explanation of the determinants of computer acceptance that is general, capable of explaining user behavior across a broad range of end-user computing technologies and user populations, while at the same time being both parsimonious and theoretically justified". Additionally, TAM provides a good framework when attempting to measure the impact of outside variables in terms of internal beliefs, attitudes, and intentions. It was developed through the identification of primary variables as they have been suggested by existing research which deals with affective determinants related to IS acceptance, and then employing the TRA methodology in a theoretical foundation for modeling these types of relationships between these variables [29].

'Perceived Usefulness' as well as 'Perceived Ease of Use' for IS acceptance behavior are of primary relevance for this model. The definition of 'Perceived Usefulness' is outlined as the user's subjective view of the probability of increasing one's work performance when employing a specified information system as it exists inside an organization. 'Perceived Ease of Use' is measured as the degree that any user anticipates that the target system is free of additional effort on their part. The TAM posits that variables outside the system may indirectly affect attitudes toward usage. This could, in turn, lead to actual system use by the influence of 'Perceived Usefulness' as well as the 'Perceived Ease of Use'. The relationships between multiple TAM elements have been validated with numerous quality empirical studies [30].

The concept of the Subjective Norm has been defined as an individual's perception that other significant people believe that he or she should or should not perform a certain behavior [31]. This particular variable was excluded by Davis in the TAM due to uncertain theoretical and psychometric status, the small effect in the areas of ease of use, and anticipated usefulness. Alternatively, Barki and Hartwick offered an alternative view. After categorizing respondents into the contexts of mandatory and voluntary use, the researchers discovered the impact of the Subjective Norm was important on intention of use in a mandatory system [32].

While the original TAM model was useful, some studies have found benefit in extending elements of the TAM. Moon and Kim butressed to extend the model in order to include factors that can be specific to the problem set. The general context, target technology factors, and 
consideration the main users of the new system can be included in the extetended factors [33][34]. Extending the TAM in this way has proven useful in other studies [35]. Thus, the TAM2 extended the initial measures of the TAM by incorporating the concept of the Subjective Norm as another type of predictor of intent when considering mandatory system use. Additionally, TAM2 employs further theoretical constructs which includes processes related to social influence and processes considered instrumentally cognitive [36]. These causal relationships as well as the elements included in the new TAM2 are outlined in Fig. 1.

Deciding the quality of the implemented IT project is definitely up to the users. The purpose of this research is to identifying the factors that influence the users' satisfaction after the M-ERP application implementation regardless of arguing if the project was completed on time and within budget. Therefore, this study focuses to fill the scholary gap by examining the end-user's usage behavior perspective after the M-ERP application implementation.

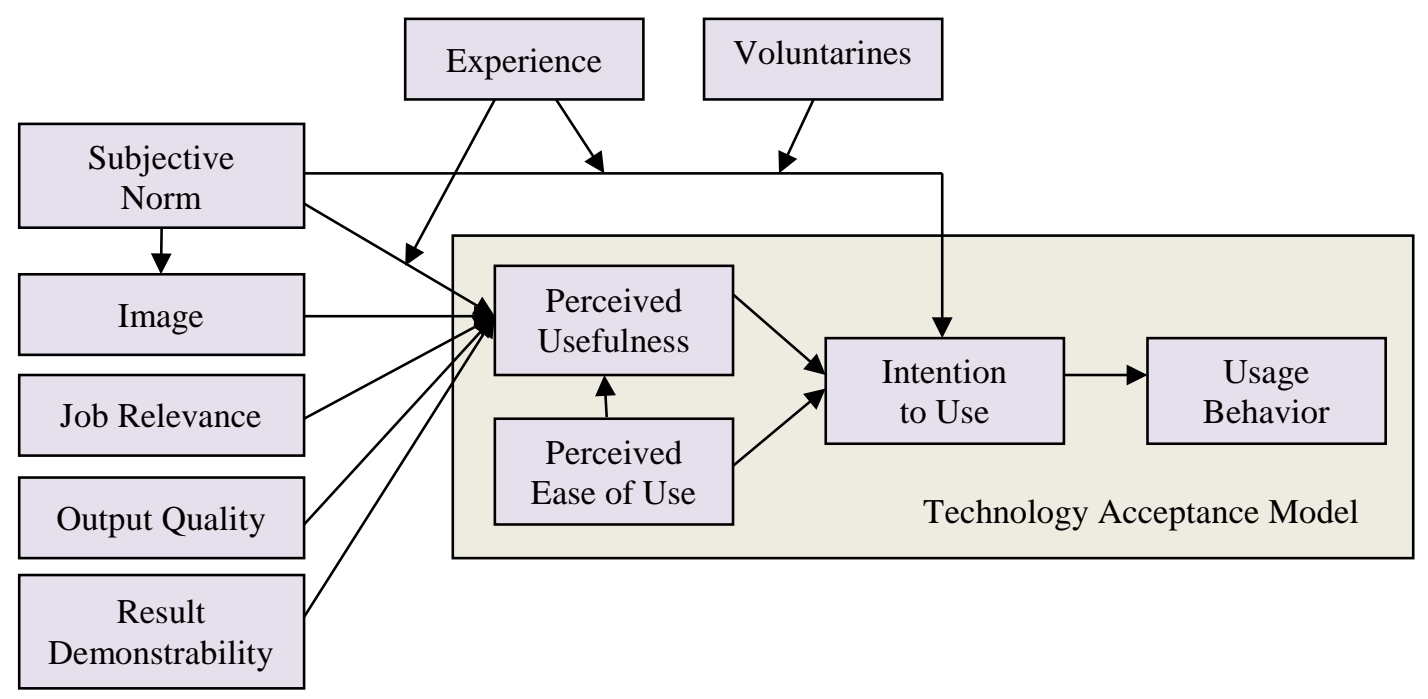

Fig. 1. Technology Acceptance Model 2 [36]

\section{Research Method and Hypotheses}

\subsection{Research Model}

To verify the hypotheses, this research project used a mixed method research approach that combined collection of data through a survey instrument, structural equation modeling (SEM). The Structural Equation Modeling (SEM) technique was used to test the research hypotheses. The SEM is a set of statistical techniques that include confirmatory factor analysis and path modeling. SEM can answer a set of interrelated research questions in an analysis by showing the relationships among multiple independent and dependent constructs simultaneously [37]. It can serve as a substitute for factor-analysis, and goodness-of-fit in regression analysis type of testing. The process of multiple regression analysis for this kind of research is painful due to the complexity of the model.

A major goal of this study was to gain new insights into how companies can plan and implement a successful mobile ERP application that satisfies the user's intention to use. In order to do this, this study sought to first validate the applicability of the TAM2. The five key 
dependent variables that were adopted from TAM2 are (a) Subjective Norm, (b) Image, (c) Job Relevance, (d) Output Quality, and (e) Result Demonstrability. Another one dependent variable which was added by adopting industry experts' suggestion is 'Compatibility'. Since the mobile devices are very sensitive to its operating system (e.g. Android vs. Apple), the Compatibility between the mobile devices and the back-end system is critical factor. The intermediate variables used for this study are (1) Perceived Usefulness, (2) Perceived Ease of Use, and (3) Intention to Use. The dependent variable which indicates users' intention to use is 'Usage Behavior'. Since all of M-ERP application users have an experience of using the traditional ERP system, the moderator of 'Experience' and 'Voluntariness' were excluded from our model. Thus, the research framework can be constructed as shown in Fig. 2.

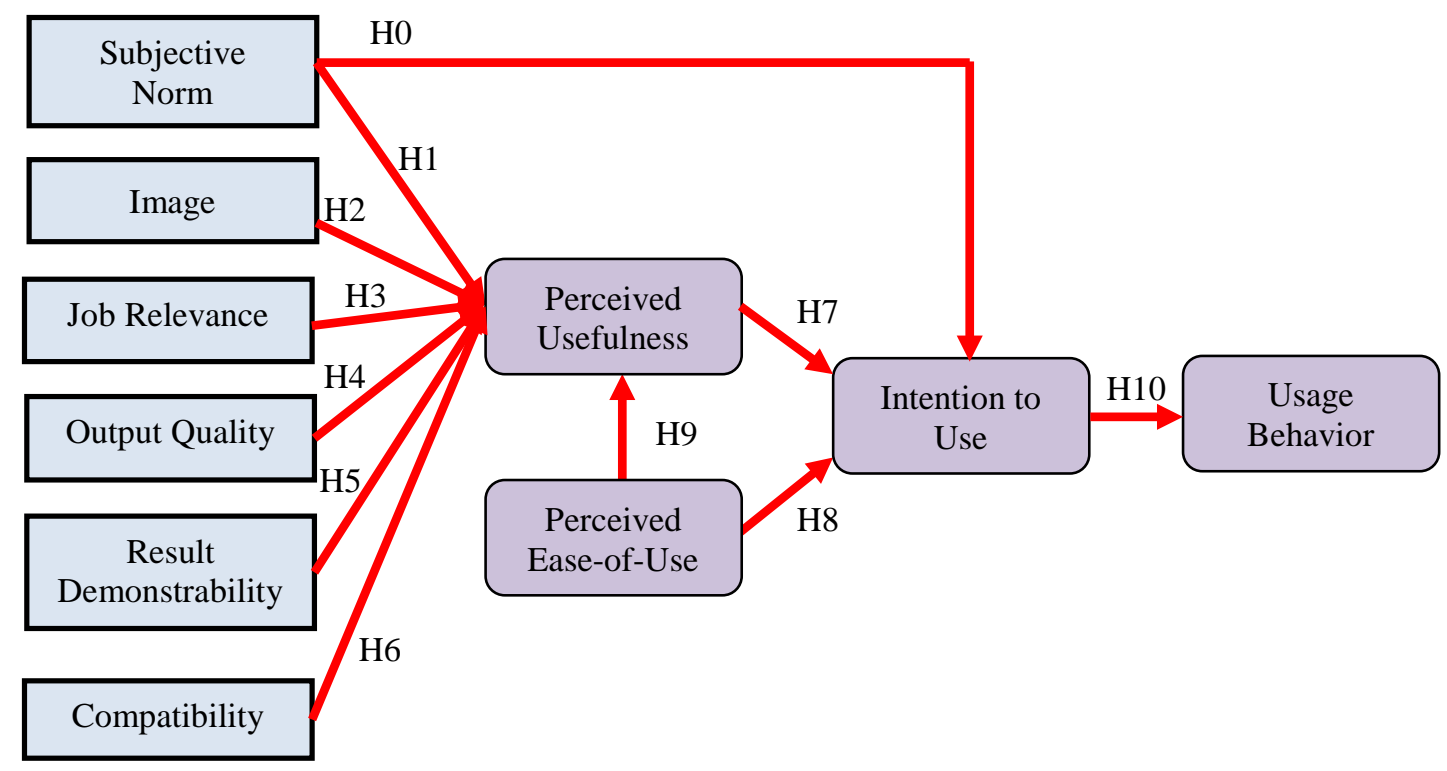

Fig. 2. Research Model

\subsection{Structural Equation Modeling (SEM)}

A structural equation modeling analysis was performed in order to test the hypotheses. The SEM is a set of statistical techniques that include confirmatory factor analysis, goodness-of-fit in regression analysis type of testing, and path modeling. SEM can answer a set of interrelated research questions in an analysis by showing the relationships among multiple independent and dependent constructs simultaneously. A typical SEM includes a 'measurement model' and a 'structural model." The former explores the relationship between observed variables and latent variables, whereas the latter examines the relationship between latent variables [38].

Using SEM, the trimmed model (i.e. modified model) was derived by modifying paths in the full model (i.e. fixed model). Then, the fit indices for both models were measured to select one competing model over another as a best-fitting model. The path analysis was followed to present a graphical path diagram in order to interpret the model. The arrows in a path diagram represent the causal dependencies within a model. The goodness-of-fit indices in SEM analysis that were used in this study is: (1) $\chi^{2}$ : Chi Square, (2) $\chi^{2}$ /df: Chi Square to Degree of Freedom Ratio, (3) TLI: Tucker Lewis Index, (4) CFI: Comparative Fit Index, (5) SRMR: 
Standardized Root Mean Square Residual, and (6) AIC: Akaike Information Criterion [39].

As mentioned earlier, the SEM specifies two models - a full and a trimmed model. For this study, the goodness-of-fit indices for both models were produced first. Then, the best-fit model between the two models was selected. Using the obtained best-fit model, the path analysis was performed using M-plus, the statistical software package for SEM. Lastly, the R2 values which indicate how well data points fit the model were represented to measure the proportion to which the model accounts for the variation of the data set.

\subsection{Hypotheses}

In previous section, the reason that the 'Experience' and 'Voluntariness' were excluded from our model was discussed. Based on the research framework that we developed above, the following 11 hypotheses were proposed:

- H0: ‘Subjective Norm' has positive impact on users' 'Intention to Use’ of M-ERP.

- H1: 'Subjective Norm' has positive impact on users' 'Perceived Usefulness' of M-ERP.

- H2: 'Image' has positive impact on users' 'Perceived Usefulness' of M-ERP.

- H3: 'Job Relevance' has positive impact on users' 'Perceived Usefulness' of M-ERP.

- H4: 'Output Quality' has positive impact on users' 'Perceived Usefulness' of M-ERP.

- H5: 'Result Demonstrability' has positive impact on users' 'Perceived Usefulness' of M-ERP.

- H6: ‘Subjective Norm' has positive impact on users' 'Intention to Use' of M-ERP.

- H7: 'Perceived Usefulness' has positive impact on users' 'Intention to Use' of M-ERP.

- H8: 'Perceived Ease of Use' has positive impact on users' 'Intention to Use' of M-ERP.

- H9: 'Perceived Ease of Use' has positive impact on users' 'Perceived Usefulness' of M-ERP.

- H10: 'Intention to Use' has positive impact on users' 'Usage Behavior' of M-ERP.

\section{Hypotheses Testing and Data Analysis}

\subsection{Data Collection and Sampling Method}

For the target population, participating organizations for this study had to have an experience of both the traditional ERP system implementation and the mobile-ERP application development within the past five years regardless of the company size. In order to obtain the company list who recently implemented the M-ERP applications having the traditional ERP system in their back-end, we contacted the ERP vendor. As a result, we obtained 15 companies from ERP vendor. Each of 15 companies were contacted via email and asked to participate in this research study. A total of 226 people participated in the main survey. The main survey was conducted on-line for a 30 day period of time (from April 15, 2015 to May 14, 2015).

\subsection{Basic Analysis of the Sample}

The collected sample comprises $52 \%$ male and $48 \%$ female subjects. This implies that the sample is collected from almost an even proportion of gender. In terms of work experience, 69 respondents had 1-5 years of work experience (46\%). The second largest set of respondents, comprising $28.7 \%$ of the group, had 6-10 years of work experience. This implies that the response rate was higher for those with less work experience. The maximum number of respondent's years of experience was 32 while the minimum work experience of any 
respondent was 1 year. The mode, the most frequently observed value for the years of work experience was 5 . The sample also shows that $53 \%$ of the respondents' companies had more than 5000 employees, 32\% had 1000-3000 employees, and 15\% had 3000-5000 employees. This indicates that the data was mostly collected from large sized companies. For the age group, most of the respondents were 30-39 years old (49\%). The second largest group fell into the 20-29 age range (26\%). Respondents over the age of 50 comprised the smallest group of only $4 \%$ of respondents. This implies that either those who fell into the 30-39 age range were also the largest age group represented within a company or this age range represented the highest group of active users of the ERP system within a specific company. The figures for these statistics are attached in appendices.

\subsection{Descriptive Statistics}

After the questionnaire was completed, the responses for each item were summed to create a score for a group of items. Then, this sum score was averaged by the number of items per variable and then by the number of the respondents in order to calculate the mean value for each variable. Along with the mean values, mode, standard deviation, variance, were also calculated and these values are represented in Table 1. Except for the variable, 'Output Quality', the values for all other variables associated with Kurtosis and Skewness were between -1 to 1 which represents that the samples were normally distributed. A rule of thumb for assessing normality for the purposes of assumption testing is that if Kurtosis and Skewness are between -1 and +1 and there is a reasonable sample size (e.g., at least 20 per cell), then one would rarely run into issues related to violations of the assumption of normality. A detailed descriptive statistics table is available in the Appendices section of this study.

Table 1. Descriptive Statistics

\begin{tabular}{|c|c|c|c|c|c|}
\hline Variable & Mean & $\begin{array}{c}\text { Standard } \\
\text { Deviation }\end{array}$ & $\begin{array}{c}\text { Sample } \\
\text { Variance }\end{array}$ & Kurtosis & Skewness \\
\hline Output Quality & 4.78 & 0.93 & 0.87 & 1.72 & -0.65 \\
\hline 2) Job Relevance & 5.04 & 1.31 & 1.73 & -0.08 & -0.55 \\
\hline Image & 4.34 & 1.32 & 1.74 & -0.19 & -0.22 \\
\hline Result Demonstrability & 4.60 & 1.20 & 1.44 & 0.32 & -0.42 \\
\hline Compatibility & 4.71 & 1.19 & 1.41 & 0.40 & -0.56 \\
\hline Subjective Norm & 4.69 & 1.09 & 1.18 & 0.21 & -0.24 \\
\hline Perceived Usefulness & 4.80 & 1.19 & 1.41 & 0.33 & -0.43 \\
\hline Perceived Ease of Use & 4.61 & 1.21 & 1.46 & 0.12 & -0.41 \\
\hline 9) Intention to Use / Use & 4.91 & 1.06 & 1.11 & -0.40 & -0.04 \\
\hline 10) Usage Behavior & 4.63 & 1.01 & 1.01 & 0.56 & -0.29 \\
\hline
\end{tabular}

\subsection{Reliability Analysis}

To estimate the reliability of the item scores for the variables, the coefficient of Cronbach's alpha was measured. It is also called the internal consistency estimate of item scores. A common rule of thumb for Cronbach's alpha is a rate of excellent if $\alpha>0.9$, and good if $0.7<\alpha$ $<0.9$. Table 2 shows that the all the items' alpha were greater than 0.7 indicating all the items were strongly consistent internally. This means that the survey questionnaire was well developed. 
Table 2. Items and Reliability

\begin{tabular}{|c|c|c|c|c|}
\hline \multicolumn{2}{|c|}{ Variable } & \multirow{2}{*}{$\frac{\text { \# of Items }}{4}$} & \multirow{2}{*}{$\begin{array}{c}\text { Items } \\
\text { rep1, rep2, out1, out2 }\end{array}$} & \multirow{2}{*}{$\frac{\text { Reliability }(\alpha)}{0.83}$} \\
\hline 1) & Output Quality & & & \\
\hline 2) & Job Relevance & 2 & job1, job2 & 0.90 \\
\hline 3) & Image & 2 & img1, img2 & 0.87 \\
\hline 4) & Result Demonstrability & 2 & res1, res2 & 0.87 \\
\hline 5) & Compatibility & 2 & comp1,comp2 & 0.89 \\
\hline 6) & Subjective Norm & 2 & sn1, sn2 & 0.91 \\
\hline 7) & Perceived Usefulness & 4 & pu1, pu2 & 0.96 \\
\hline 8) & Perceived Ease of Use & 3 & peou1,peou2 & 0.91 \\
\hline 9) & Intention to Use / Use & 4 & itu1, itu2 & 0.87 \\
\hline 10) & Usage Behavior & 3 & ub1, ub2, ub3 & 0.91 \\
\hline
\end{tabular}

\subsection{Structured Equation Modeling (SEM) Analysis}

Table 3 shows the fit indices for both the full and the trimmed models in the sample. These two models needed to be evaluated with the goodness-of-fit indices to determine if they fit the sample well. In the full model, the $\chi 2 / \mathrm{df}$ ratio (2.997) and the SRMR (0.069) met the desired level of goodness-of-fit indices $(\chi 2 / \mathrm{df}<3$, SRMR $<0.08)$. However, the other fit indices of CFI (0.891) and TLI (0.836) did not satisfy the desired level of values (CFI $>0.9$, TLI $>0.9$ ).

Table 3. Full and Trimmed Model of SEM

\begin{tabular}{cccccccc}
\hline SEM Model & $\chi 2$ & DF & $\chi 2 / D F$ & CFI & TLI & SRMR & AIC \\
\hline Full & 149.856 & 50 & 2.997 & 0.891 & 0.836 & 0.069 & 2631.965 \\
Trimmed & 119.770 & 41 & 2.921 & 0.923 & 0.903 & 0.058 & 2233.051 \\
\hline
\end{tabular}

Therefore, the trimmed model was also examined in order to find a better fit between these two SEM models. In order to obtain the trimmed model, the path between the independent variables, 'Output' and 'Perceived Usefulness' was adjusted by setting the value to zero. This adjustment process was continued in order to examine if another adjustment of the path might offer a better fit for the sample. In the trimmed model, the all the fit indices of $\chi^{2} / \mathrm{df}$ ratio (2.921), CFI (0.923), TLI (0.903), and SRMR (0.058) satisfied the desired level $(\chi 2 / \mathrm{df}<3$, CFI $>0.9$, TLI $>0.9$, SRMR $<0.08)$. The model that has a lower AIC is preferred for the best-fit model (Kline, 1998). As seen in Table 3, the trimmed model had a lower AIC (2233.051) than that of the full model (2631.965). Thus, the trimmed model was selected as the best-fit model in order to find the relationship of the variables in the sample.

\subsection{Path Analysis}

As noted in the previously, the SEM is a hybrid technique that includes aspects of confirmatory factor analysis, regression, and path analysis. The path analysis was performed using the best-fit model that was obtained from above step, and as a result, the graphical path diagram was created. A diagram of this model is shown in Fig. 3.

The path diagram indicates that only three out of six factors have a positive impact on 'Perceived Usefulness' ( $p<0.05$ ). These three factors are - (1) Subjective Norm, (2) Output, and (3) Job Relevance. 'Subjective Norm' is the factor that has the most significant effect on 'Perceived Usefulness'. 


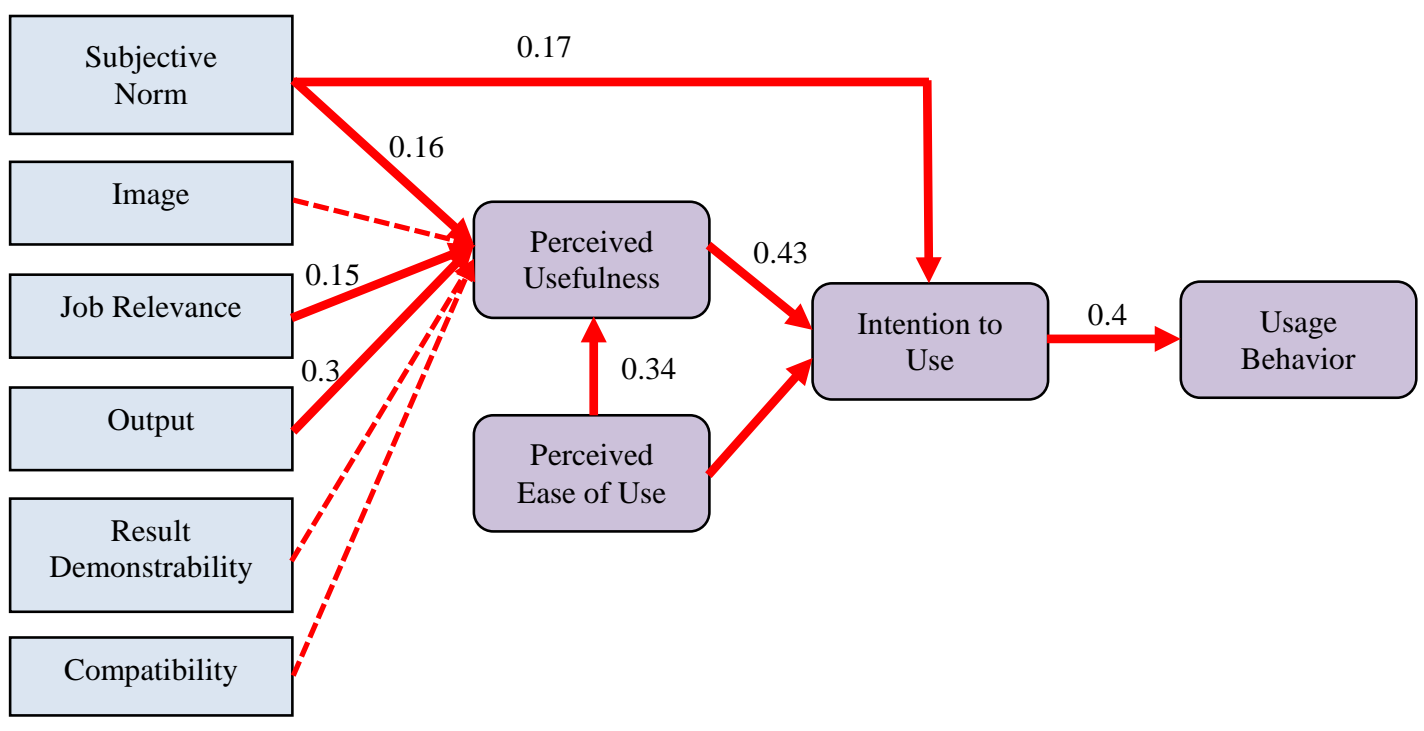

Fig. 3. Path Diagram for SEM Model

\subsection{Results of Hypotheses Testing}

As discussed in the previous section, three out of eleven hypotheses were rejected. Table 3 summarizes the results of hypotheses.

Table 4. Summary of Hypothesis Testing

\begin{tabular}{|l|l|l|}
\hline No. & Alternate Hypothesis & Result \\
\hline H0 & 'Subjective Norm' has positive impact on users' 'Intention to Use'. & Accepted \\
\hline H1 & 'Subjective Norm' has positive impact on users' 'Perceived Usefulness'. & Accepted \\
\hline H2 & 'Image' has positive impact on users' 'Perceived Usefulness'. & Rejected \\
\hline H3 & 'Job Relevance' has positive impact on users' 'Perceived Usefulness'. & Accepted \\
\hline H4 & 'Output Quality' has positive impact on users' 'Perceived Usefulness'. & Accepted \\
\hline H5 & 'Result Demonstrability' has positive impact on users' 'Perceived Usefulness'. & Rejected \\
\hline H6 & 'Compatibility' has positive impact on users' 'Perceived Usefulness'. & Rejected \\
\hline H7 & 'Perceived Usefulness' has positive impact on users' 'Intention to Use'. & Accepted \\
\hline H8 & 'Perceived Ease of Use' has positive impact on users' 'Intention to Use'. & Accepted \\
\hline H9 & 'Perceived Ease of Use' has positive impact on users' 'Perceived Usefulness'. & Accepted \\
\hline H10 & 'Intention to Use' has positive impact on users' 'Usage Behavior'. & Accepted \\
\hline
\end{tabular}

As seen in Table 4, all hypotheses except H2, H5, and H6 were accepted. This implies that not all the factors in the model have significant impacts on user's usage behavior. It indicates that the 'Image' and 'Job Demonstrability' did not have an effect on 'Perceived Usefulness' as it was designed in TAM2. 


\section{Conclusion}

The study extended the research by Lee (2015) to investigate the applicability of TAM2 onto the mobile-ERP user behavior [40]. In order to achieve this goal, the structural equation modeling technique was adopted to test the interactions between the constructs. After analysis of the data, this study found that the five critical success factors that Davis identified in TAM2 had a significant impact on 'Perceived Usefulness' did not work for the factors: 'Image' and 'Result Demonstrability'. Moreover, the 'Compatibility' which was not adopted from TAM2 but from industry experts that they expected to have a significant impact on 'Perceived Usefulness' did not work either. Thus, these are not helpful in understanding or predicting the user's adoption of the mobile-ERP applications. Based on the results in previous chapter, the following conclusions were proposed.

Using a diverse set of data, the three out of five factors in the proposed model: (1) Subjective Norm, (2) Job Relevance, (3) Output are the key factors in understanding the users' behavior of the mobile-ERP applications. The result discovered that the 'Subjective Norm' has the most significant impact on 'Perceived Usefulness'. This implies that the beliefs of people important to application users will affect users' tendency of using mobile-ERP applications. Therefore, it can be inferred that if people important to a user consider that it is necessary to use mobile-ERP applications, the user is more likely to perceive the mobile-ERP applications as useful. In terms of 'Job relevance', it is found that a potential user judges the effects of using a mobile-ERP application if it enhances his/her performance. This study also found that the quality of 'Output', which is the degree to which one thinks that a new system can perform required tasks, is also a key determinant for users' behavior.

Overall, the results represented that except for the effect of 'image' on 'perceived usefulness', and 'result demonstrability' on 'perceived usefulness', all the other social influence processes of TAM2 influence user's perception of the degree of interaction by mobile-ERP applications.

The implementation of a mobile-ERP application does not guarantee a positive impact on the organization in terms of cost reductions or revenue/profit increase. As one of the potential factors for a successful mobile-ERP application implementation, this study considered usage behavior of the system, which was the user's intention to use the newly developed application for the M-ERP. The findings will provide directions for organizations to plan and implement mobile-ERP applications to support users' intention to use.

\section{References}

[1] Gnanasambandam, S., "Enterprise Mobility - 10 Critical Success Factors,” Research at Infosys Labs, 2013. Retrived from: http://www.infosysblogs.com/infosys-labs/2013/07/ enterprise_mobility-tencrit.html

[2] Markus, M, Tanis, C., \& Fenema, P., "Enterprise resource planning: multisite ERP implementations," Communications of the ACM, 43(4), 42-46, 2000. Article (CrossRef Link)

[3] Krigsman, M., “2013 ERP research: Compelling advice for the CFO,” ZDNet, 2013. Retrived from: http://www.zdnet.com/article/citrix-replacement-for-microsoft-azure-remoteapp-is-coming -in-2017/

[4] Kanaracus, C., "Majority of ERP Software Projects Still Over Time and Budget, Survey Finds," IDG News Service, 2014. Retrived from: http://www.cio.com/article/2378191/ enterprise-resource-planning/majority-of-erp-software-projects-still-over-time-and-budget--surve y-fi.html

[5] IDC, U.S. mobile worker forecast 2015-20, 2015. Retrived from: https://www.idc.com/ getdoc.jsp?containerId=prUS25705415 
[6] Clemens, B., Cata, T., \& Hackbarth, G., "Mobile Device Considerations for Supply Chain and ERP Related Systems,” IBIMA Publishing, 151480, 16, 2012. Article (CrossRef Link)

[7] Kimberling, E., "2013 ERP report: What our new research reveals about ERP systems,” 2013. Retrived from: http://panorama-consulting.com/2013-erp-report-what-our-new- research-reveals -about-erp-systems/.

[8] Davis, F., "Perceived Usefulness, Perceived Ease of Use, and User Acceptance of Information Technology,” MIS Quarterly, 13(3), 319-340, 1989. Article (CrossRef Link)

[9] Roberts, D., "What use is mobile ERP?", Cambashi, 2011. Retrived from: http://www.cambashi.com/stuff/contentmgr/files/0/fe6b5ded2ca7689fcd0da2ff25d7e042/downlo ad/what_use_is_mobile_erp.pdf

[10] Koch, C., “Enterprise resource planning,” Journal of Organizational Change Management, 14(1), 64-78, 2001. Article (CrossRef Link)

[11] Brazel, J. F., \& Dang, L., "The effect of ERP system implementations on the management of earnings and earnings release dates,” Journal of Information Systems, 22(2), 1-21, 2008. Article (CrossRef Link)

[12] Ifinedo, P., “An investigation of the impacts of some external contextual factors on ERP system success assessment: a case of firms in Baltic-Nordic region,” International Journal of Internet and Enterprise Management, 4(4), 355-378, 2006. Article (CrossRef Link)

[13] Wang, E. \& Chen, J., "Effects of internal support and consultant quality on the consulting process and ERP system quality,” Decision Support Systems, 42(2), 1029-1041, 2006. Article (CrossRef Link)

[14] Allied Market Research, "Global ERP Software Market - Size, Industry Analysis, Trends, Opportunities, Growth and Forecast, 2013-2020,” 2015. Retrived from: https://www.alliedmarketresearch.com/ERP-market

[15] Rettig, C., “The trouble with Enterprise software,” MIT Sloan Management Review, 49(1), 20-27, 2007.

[16] Batra, S., "Impact of information technology on organizational effectiveness: a conceptual framework incorporating organizational flexibility," Global Journal of Flexible Systems Management, 7(1-2), 15-25, 2006.

[17] Tsai, W., Shaw, M., Fan Y., Liu, J., Lee, K., \& Chen, Hui., “An empirical investigation of the impacts of internal/external facilitators on the project success of ERP: A structural equation model,” Decision Support Systems, 50(2), 480-490, 2011. Article (CrossRef Link)

[18] Chung, B., “An analysis of success and failure factors for ERP systems in engineering \& construction firms," A Doctoral dissertation, Available from Digital Repository at the University of Maryland (UMI-UMD-4917), 2007.

[19] Beatty, R., \& Williams, C., "ERP II: Best practices for successfully implementing an ERP upgrade," Communications of the ACM, 49(3), 105-109, 2006. Article (CrossRef Link)

[20] Chen, R-S., Sun, C-M., Helms, M., \& Jih, W-J., "Role negotiation and interaction: An exploratory case study of the impact of management consultants on ERP system implementation in SMEs in Taiwan,” Information Systems Management, 25(2), 159-173, 2008. Article (CrossRef Link)

[21] Hsiao, Y-D., Yang, C-C., Lin, W-T., \& Lee, W., “A study on key failure factors for introducing enterprise resource planning,” Human Systems Management, 26(2), 139-152, 2007.

[22] Gefen, D., \& Ragowsky, A., "A multi-level approach to measuring the benefits of an ERP system in manufacturing firms,” Information Systems Management, 22(1), 18-25, 2005. Article (CrossRef Link)

[23] Zwikael, O., \& Globerson, S., "From critical success factors to critical success processes," International Journal of Production Research, 44(17), 3433-3449, 2006. Article (CrossRef Link)

[24] Chung, B., Skibniewski, M., Lucas, H.,Jr., \& Kwak, Y., “Analyzing enterprise resource planning system implementation success factors in the engineering-construction industry," Journal of Computing in Civil Engineering, 22(6), 373-382, 2008. Article (CrossRef Link)

[25] Chen, R-S., Sun, C-M., Helms, M., \& Jih, W-J., "Role negotiation and interaction: An exploratory case study of the impact of management consultants on ERP system implementation in SMEs in Taiwan,” Information Systems Management, 25(2), 159-173, 2008. Article (CrossRef Link) 
[26] Kurbel K., Jankowska, A., \& Nowakowski, K., “A Mobile User Interface for an ERP System,” Issues in Information Systems, VII(2), 146-151, 2006.

[27] Enterprise mobility management, (n.d.), In Wikipedia, Retrieved from: https://en.wikipedia.org/wiki/Enterprise_mobility_management

[28] Rimini Street, “Mobility Solutions for ERP," 2015. Retrived from: https://www.riministreet.com/Documents/Collateral/Rimini-Street-White-Paper-Mobility-Solutio ns-for-ERP.pdf

[29] Davis, F., Bagozzi, R., \& Warshaw, P., "User acceptance of computer technology: A comparison of two theoretical models,” Management Science, 35(8), 982-1003, 1989. Article (CrossRef Link)

[30] Legris, P., Ingham, J., \& Collerette, P., "Why do people use information technology? A critical review of the technology acceptance model," Information and Management, 40(2), 191-204, 2003. Article (CrossRef Link)

[31] Rhodes, R., \& Courneya, K., "Investigating multiple components of attitude, subjective norm, and perceived control: An examination of the theory of planned behaviour in the exercise domain," British Journal of Social Psychology, 42(1), 129-146, 2003. Article (CrossRef Link)

[32] Barki, H., \& Hartwick, J., "Interpersonal conflict and its management in information systems development,” MIS Quarterly, 25(2), 195-218, 2001. Article (CrossRef Link)

[33] Moon, J., \& Kim, Y., "Extending the TAM for a world-wide-web context," Information \& Management, 38(4), 217-230, 2001. Article (CrossRef Link)

[34] Tarhini, A., Hone, K., \& Liu, X., "Extending the TAM model to empirically investigate the students' behavioural intention to use e-learning in developing countries," Science and Information Conference 2013, London, U.K, 2013.

[35] Pasaoglu, D., “Analysis of ERP usage with technology acceptance model,” Global Business and Management Research, 3(2), 157-165, 2011.

[36] Davis, F. \& Venkatesh, V., "A theoretical extension of the technology acceptance model: four longitudinal field studies,” Journal of Management Science, 46(2), 186-204, 2000. Article (CrossRef Link)

[37] Gefen, D., Straub, D., \& Boudreau, M., "Structural Equation Modeling and Regression: Guidelines for Research Practice," Communications of the Association for Information Systems, 4(7), 1-70, 2000.

[38] Wu, M., Chou, H., Weng, Y. \& Huang, Y., “TAM2-based Study of Website User Behaviour,” WSEAS Transactions on Business and Economics, 4(8), 133-151, 2011.

[39] Lee, S., “A Preliminary Modeling for an ERP System Implementation in a Multi-industry Context,” Journal of Korean Institute of Next Generation Computing, 10(4), 77-88, 2014.

[40] Lee, S., "User behavior of mobile enterprise applications," in Proc. of ICONI 2015 Symposium, Kuala Lumpur, Malaysia, 2015.

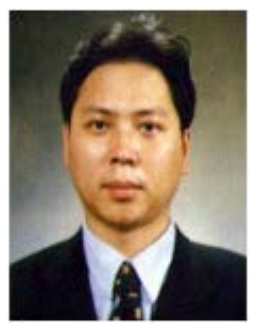

Sangmin Lee received a Ph.D. in Engineering Management, an M.S. in Computer Science from the George Washington University, and B.S. in Computer Science from Indiana State University. He is an assistant professor at School of Business Administration at Soongsil University, Seoul, Korea. Prior to joining Soongsil University, he served as Chief Information Officer at HCPA, PLC, Washington,D.C, USA. Prior to HCPA, he was a Senior Analyst at the Standard \& Poor's, New York, USA. His current research interest includes mobile enterprise applications, supply chain management, quality management, big data analysis, e-Learning, business intelligence, business continuity management, finTech, and Internet of Things. 